\title{
International Vision Screening: Results from Alexandria, Egypt
}

\author{
Mahmoud Elsahn
}

Published online: 24 September 2014

(C) Springer Science + Business Media New York 2014

\begin{abstract}
Amblyopia and refractive errors are the two most common causes of visual impairment in young children. Amblyopia usually affects only one eye thus making it difficult for the parents to detect as the child relies on their better sighted eye. The need for early intervention is crucial since the critical period of the visual development is at an early age. Thus, efforts are made to detect and treat those children who require intervention through vision screening programs for school/preschool children who would be missed otherwise. These programs help in detecting amblyopia and refractive errors, but studies on which age they should be performed and the evidence of effectiveness are few. This creates a problem when utilizing human and financial resources especially in limitedincome countries. Different protocols have been used in various programs including visual acuity tests, binocular assessment such as using stereoacuity tests, ocular misalignment detection, and color vision assessment. This paper explores the rationale behind commencing a vision screening program in Alexandria Egypt and its results.
\end{abstract}

\section{Keywords Vision $\cdot$ Screening $\cdot$ Egypt $\cdot$ Alex eye} Children

\section{Introduction}

Children are society's most valuable resource. They are today's future and tomorrow's hope. In order to have a

M. Elsahn ( $\square)$

Alex Eye Center, 64 Ismail Serry Street, Smouha, Alexandria, Egypt

e-mail: melsahn@gmail.com productive community, attention should be given to optimize the health of children.

A child with a visual disability constitutes a problem for the child and his/her family through education interference, lower earnings, and decreased employment opportunities [1-3]. The World Health Organization (WHO) estimated that "blindness costs billions of dollars in lost productivity, rehabilitation, caring for blind people and special education", thus affecting the whole community [4].

Various vision screening programs for children have been embedded in the educational systems of many countries. These programs target the visual morbidities that could be prevented in many cases through easy, low cost measures if provided at the appropriate time during childhood [5].

In developing countries, limited data is available on the magnitude of the childhood vision problem where epidemiological research and whole population surveys are needed to document the causes and the prevalence.

According to the WHO, 1.4 million cases of childhood blindness below the age of 15 are currently present. About one-half of this estimate could have been avoided with early intervention [3,6]. Childhood blindness is the second largest cause of blindness after cataracts. Approximately 500,000 children become blind every year (one every minute). One of the main causes of visual impairment is uncorrected refractive errors, children who need glasses do not have them [7]. Uncorrected refractive errors can lead to amblyopia, which is defined as reduced visual acuity in the absence of eye pathology. It is estimated to affect between 2 and $4 \%$ of children $[4,5,8]$. Screening for amblyopia early in childhood (preschool age) is now utilized and recommended in many countries to ensure that affected children are detected and treated as early as possible, [9, 10] and to correct the vision in their amblyopic eye to a 
level that would be useful in case vision in their other better sighted eye is lost for any reason later in life [11, 12].

For all the above reasons, vision screening has been an integral part of the education system in many countries across the globe. The primary aim of vision screening is to identify those who have uncorrected refractive errors and identify those who require amblyopia treatment [13, 14]. Although some major reviews have questioned the value of the screening programs in schools, $[11,15]$ others have shown their value in detecting not only uncorrected refractive errors and amblyopia but also in detecting other causes of impaired vision such as cataracts and strabismus for instance [7, 16, 17•].

In developing countries, screening programs are of high importance because school children who are identified to need glasses would not otherwise have had access to eye care [18]. Meanwhile, data collected solely from school children samples are not representative of the population as a whole [19]. According to UNESCO, "61 million primary school-aged children were not enrolled in school in 2010. Of these children, $47 \%$ were never expected to enter school". This means that identifying all children who could benefit from early eye treatment cannot happen only in the school environment.

\section{Screening and Vision 2020}

Screening is defined by the NHS as "a service in which members of a defined population, who do not necessarily perceive they are at risk of, or are already affected by a disease or its complications, are identified to reduce the risk of this disease or its complications" [20]. Amblyopia has now been identified as a major issue that has socioeconomic consequences to the community [5]. Screening of vision through visual acuity testing targets those children who are at risk of developing amblyopia [17•].

The World Health Organization (WHO) and the International Agency for the Prevention of Blindness (IAPB) established a global initiative 'VISION 2020 fight to sight' for the elimination of avoidable blindness, through a joint program with international NGOs and corporations. In order to proceed with the initiative, epidemiology research and whole population surveys should be developed to identify the present magnitude, potentially high-risk groups, and the major causes responsible for childhood visual impairment. These studies could then inform a more feasible plan and efficient strategies to implement a vision screening program [21].

\section{Organizing the Program}

As a contribution to the Egyptian society in order to help lower the incidence of visual impairment in school children, a pilot study was performed by the department of pediatric ophthalmology at Alex Eye Center in Alexandria Egypt. In this study, 6,029 students in the elementary education of seven governmental schools throughout the governorate of Alexandria were screened for vision problems.

The aims of this study were to analyze the various causes of impaired visual acuity in elementary school children, to detect the incidence of each cause, and to determine the effectiveness of the new elementary vision screening program.

The program included a stepwise approach to identify and treat those who have undiagnosed visual impairment.

Schools were chosen to represent specific ages and geographic locations to represent most of the Alexandria population. The research team worked with the schools' administrations to enhance participation. The school principal was notified of the date when the vision screening technicians would be visiting the school making sure that all the students should be available on that date.

\section{Screening Assessment}

On the day of the visit, students were tested individually by a well-trained technician for:

1. Best-corrected monocular visual acuity using Snellen or Tumbling E optotypes visual acuity charts depending on their age.

2. Any manifest eye misalignment

Those who scored less than 6/12 (20/40) in one or both eyes or had ocular alignment problems were referred to the Alex Eye Center for a full ophthalmic examination at no cost to the patient or their family.

\section{Comprehensive Ophthalmological Examination}

In the eye clinic, referred children received a comprehensive eye examination by a pediatric ophthalmologist including:

- Visual acuity testing

- Thorough slit-lamp examination

- Strabismus assessment

- Autorefraction

- Manifest refraction

- Cycloplegic refraction

- Dilated fundus examination 


\section{Study Results}

The Alex Eye vision screening program was offered to 6,029 students in the elementary schools. Students' ages ranged from 6 to 12 years old. Six \% (361) were referred to the eye clinic at Alex Eye Center for failing the screening test (failed visual acuity and/or eye misalignment). None of the referred children had been previously identified as having a visual defect.

Seventy seven $(22 \%)$ of the vision screen failures were found to have myopia ranging from -0.50 to -12.75 diopters. One hundred and ninety (52\%) of the vision screen failures were found to have hyperopia ranging from +0.75 to +8.75 diopters. Thirty five $(10 \%)$ of the vision screen failures were found to have pure astigmatism ranging from 0.75 to 5.50 diopters.

Eleven subjects had anisometropia of four or more diopters difference between the two eyes, eight had amblyopia, eight had strabismus (seven with esotropia and one with exotropia), one had nystagmus, one had unilateral optic atrophy, and twenty six had pseudomyopia (defined in this study as a difference of four diopters between the pre-cycloplegic myopic manifest refraction and the cycloplegic refraction) of which fourteen had unilateral pseudomyopia. Four $(1 \%)$ of the referred students did not complete the full ophthalmic examination stating that they would receive eyecare elsewhere (Table 1).

Three hundred and two students of the 361 who failed the vision screen achieved 6/6 (20/20) best-corrected visual acuity with spectacle correction. The twenty six students who had pseudomyopia achieved 6/6 (20/20) without spectacle prescription after instillation of cycloplegic eye drops. While the remaining twenty nine had eye pathologies that needed further follow-up and/or intervention beyond the scope of this report.

Table 1 Ocular diagnoses found in the Alex Eye vision screening program

\begin{tabular}{ll}
\hline Ocular findings & No $(\%)$ of children $(n=361)$ \\
\hline Myopia & $77(22 \%)$ \\
Hyperopia & $190(52 \%)$ \\
Pure astigmatism & $35(10 \%)$ \\
Anisometropia $>4 \mathrm{D}$ & $11(3 \%)$ \\
Amblyopia & $8(2 \%)$ \\
Strabismus & $8(2 \%)$ \\
Pseuodmyopia & $26(7 \%)$ \\
Others & $6(2 \%)$ \\
\hline
\end{tabular}

\section{Analysis}

In Egypt, students in elementary education receive vision checks during their school year, as a form of screening for amblyopia. For underperforming children who have vision less than 6/12 (20/40) in one or both eyes, parents are notified to take their children to the ophthalmologist.

Although the role of vision screening of school-aged students remains controversial, as the quality of evidence on the effectiveness of screening is low, $[15,22 \bullet \cdot, 23]$ this does not mean that screening is of no value $[6,12]$. Where primary eye care services are limited, it is of high value to screen the children in schools, offering the opportunity to identify children with a problem that would be missed otherwise. Such problems can be severe before they can even be noticed.

In our study, $6 \%$ of the screened children needed referral, of which $87 \%$ had refractive errors $5 \%$ of the screened children needed only glasses to achieve a bestcorrected visual acuity of 6/6 (20/20) in both eyes). However, all of the children in our study had received previous vision checks during their school period as part of the usual school program. This raises questions about how the original school vision check was done and if it was performed properly in the first place.

We hypothesize the following reasons for the prior false negative vision checks performed by the school:

- The person performing the screening is not abiding by strict guidelines as to who should be referred to the eye clinic for further examination.

- While performing the test, students may not fully occlude the eye not being tested leading to binocular viewing of the chart giving false results of good vision.

- Parents when notified of failed vision check are not fully informed of the magnitude of the potential reasons.

- Parents know the magnitude of the problem but chose not to proceed further with a medical examination due to economic reasons, cultural, or social rejection of eyeglasses.

- Absent students on the day of screening are not retested and are thus not found.

- Some schools were unintentionally missed during the organization of the schedule of the national program.

In our cohort study of school children, the prevalence of amblyopia was measured at $0.1 \%$. In comparison with different countries from different regions, the prevalence of amblyopia in Sweden was measured at $0.2 \%$, [24, 25] Amblyopia prevalence in Israel was noted to be $1.0 \%$, [26] with Singapore at $1.2 \%$, [27] and Japan t at $0.2 \%$ [28, 29]. 
The prevalence of strabismus in school children was measured at $0.1 \%$ in our study, while reports from US primary school children measured the prevalence at $1.7 \%$, [30] Australia at $0.3 \%$ [31], Japan at $1 \%$ [28, 29], and Singapore at $0.8 \%$ [27].

\section{Conclusion}

Vision screening is mandated in many schools in developed and developing countries, but evidence of effectiveness of the programs is to be validated and quantified for the value of detecting amblyopia and/or refractive errors as well as the cost effectiveness when applied on an international scale. There is vague evidence regarding the optimum age for screening and the frequency at which it should be done. A general agreement has been set that the younger the age at screening, the better in establishing and regaining optimum vision. Today's trends have been shifted toward screening of the preschool children starting from the age of 3 , but there is still the problem in which an effective method or battery is to be developed. At this young age, a subjective method in determining the visual acuity is difficult to achieve with every child. We are in need of an objective way with high efficiency, reproducibility, speed, and ease of use while not operator dependent. There are a multitude of instrument-based vision screeners with more in development making it hopeful that technology will improve the testing characteristics [32 33, 34•, 35].

It is also necessary to set the goals and the targets of the screening programs. If the goal is to detect and treat amblyopia, then younger ages should be targeted. This should be performed in preschools, the mother/child wellbeing offices, and family medicine practices.

But if the aim is to detect those children who have refractive errors that lead to impaired vision, then schoolaged children (6-12 years) are the ones to be screened. Regular checkups should be mandated at certain ages in order to detect those children who develop visual impairment during their development, especially at the age of 8-12 years old where refractive errors often interfere with the child's ability to learn.

Special attention should be given to the personnel performing the screening programs. They should be qualified and trained well in order to eliminate the errors of not detecting those who require referrals or refer those who do not need referrals [36].

A structure should be put in place to provide proper identification of the children at risk of developing visual impairment. This should be done through several measures:

1. Establishment of a health needs assessment including service planning and informed commissioning which would allow for appropriate targeting of resources and providing intervention for those in need.

2. Providing a basis for developing and evaluating the screening programs: by establishing and continuously providing epidemiology and effectiveness studies.

Acknowledgment The author acknowledges the efforts of the pediatric ophthalmology department at Alex Eye Center and Oyoun Foundation, with special thanks to Amal ElSehimy, MD, Maha ElBasha, MD and Rasha Abdou, MD for their joint efforts in examining the referred children and providing the best care thereafter.

Disclosure Dr. Mahmoud Elsahn has received funding from Alex Eye Center for this study.

Human and Animal Rights and Informed Consent This article does not contain any studies with human or animal subjects performed by any of the authors.

\section{References}

Papers of particular interest, published within the last 3 years, have been highlighted as:

- Of importance

-• Of major importance

1. Taylor HR. Refractive errors: magnitude of the need. Community Eye Health. 2000;13:1-2.

2. Helveston EM, Weber JC, Miller K, Robertson K, Hohberger G, Estes R, et al. Visual function and academic performance. Am J Ophthalmol. 1985;99(3):346-55.

3. Rosner J, Rosner J. Some observations of the relationship between the visual perceptual skills development of young hyperopes and age of first lens correction. Clin Exp Ophthalmol. 1986;69:166-8.

4. World Health Organization. Elimination of avoidable visual disability due to refractive errors. WHO/PBL/00.79 2000.

5. WHO Refractive Error Working Group. Report on strategic planning meeting of refractive error working group. 2002:1-30.

6. Gilbert C, Awan H. Blindness in children: half of it is avoidable, and suitable cost effective interventions are available. BMJ. 2003;327(7418):760.

7. He M, Zeng J, Liu Y, Xu J, Pokharel G, Ellwein LB. Refractive error and visual impairment in urban children in Southern China. Invest Ophthalmol Vis Sci. 2004;45:793-9.

8. Mulvihill A, Bowell R, Lanigan B, O'Keefe M. Uniocular childhood blindness: a prospective study. J Pediatr Ophthalmol Strabismus. 1996;34(2):111-4.

9. Donahue SP, Arnold RW, Ruben JB, AAPOS Vision Screening Committee. Preschool vision screening: what should we be detecting and how should we report it? Uniform guidelines for reporting results of preschool vision screening studies. J. AAPOS. 2003;10:314-6.

10. Dutton GN, Cleary M. Should we be screening for and treating amblyopia? BMJ. 2003;327(7426):1242-3.

11. Snowden SK, Stewart-Brown SL. Preschool vision screening. Health Technol Assess. 1997;1(8):1-83.

12. Clarke MP, Wright CM, Hrisos S, Anderson JD, Henderson J, Richardson SR. Randomised controlled trial of treatment of 
unilateral visual impairment detected at preschool vision screening. BMJ. 2003;327(7426):1251.

13. Cummings GE. Vision screening in junior schools. Public Health. 1996;110:369-72.

14. Ciner EB, Schmidt PP, Orel-Bixler D, Dobson V, Maguire M, Cyert L, Moore B, Schultz J. Vision screening of preschool children: evaluating the past, looking toward the future. Optom Vis Sci. 1998;75(8):571-4.

15. Hall DMB, Elliman D. Health for all children. 4th ed. Oxford: Oxford University Press; 2003.

16. Dandona R, Dandona L, Srinivas M, Sahare P, Narsaiah S, Munoz SR, Pokharel GP, Ellwein LB. Refractive error in children in a rural population in India. Invest Ophthalmol Vis Sci. 2002;43(3):615-22.

17. - Hunter DG. Targeting treatable disease-not just risk factors-in pediatric vision screening. J AAPOS 2013;17:2-3. It outlines the updated recommendations of the AAPOS on the preschool vision screening devices.

18. Christine P, Hatt SR. Vision screening for amblyopia in childhood. Cochrane Database Syst Rev (2009) 3.

19. Negrel AD, Maul E, Pokharel GP, Zhao J, Ellwein LB. Refractive Error Study in Children: sampling and measurement methods for a multi-country survey. Am J Ophthalmol. 2000;129:421-6.

20. Simmers AJ, Gray LS, Spowart K. Screening for amblyopia: a comparison of paediatric letter tests. $\mathrm{Br} \mathrm{J}$ Ophthalmol. 1997;81:465-9.

21. Resnikoff S, Pararajasegaram R. Blindness prevention programmes: past, present, and future. Bull World Health Organ. 2001;79(3):222-6.

22. • Mathers M, Keyes M, Wright M. A review of the evidence on the effectiveness of children's vision screening. Child Care Health Dev 2010;36:756-80. It compares different screening programs from different countries and the different modalities used in each country .

23. Hopkins S, Sampson GP, Hendicott P, Wood JM. Review of guidelines for children's vision screenings. Clin Exp Optom. 2013;96(5):443-9.

24. Kvarnström G, Jakobsson P, Lennerstrand G. Visual screening of Swedish children: an ophthalmological evaluation. Acta Ophthalmol Scand. 2001;79(3):240-4.
25. Jensen H, Goldschmidt E. Visual acuity in Danish school children. Acta Ophthalmol. 1986;64(2):187-91.

26. Eibschitz-Tsimhoni M, Friedman T, Naor J, Eibschitz N, Friedman Z. Early screening for amblyogenic risk factors lowers the prevalence and severity of amblyopia. J AAPOS. 2000;4(4):194-9.

27. Chia A, Dirani M, Chan Y-H, Gazzard G, Au Eong K-G, Selvaraj $\mathrm{P}$, Ling Y, et al. Prevalence of amblyopia and strabismus in young Singaporean Chinese children. Invest Ophthalmol Vis Sci. 2010;51(7):3411-7.

28. Matsuo T, Matsuo C. The prevalence of strabismus and amblyopia in Japanese elementary school children. Ophthalmic Epidemiol. 2005;12(1):31-6.

29. Matsuo T, Matsuo C. Comparison of prevalence rates of strabismus and amblyopia in Japanese elementary school children between the years 2003 and 2005. Acta Med Okayama. 2007;61(6):329.

30. Morgan KS, Kennemer JC. Off-axis photorefractive eye screening in children. J Cataract Refract Surg. 1997;23(3):423-8.

31. Junghans B, Kiely PM, Crewther DP, Crewther SG. Referral rates for a functional vision screening among a large cosmopolitan sample of Australian children. Ophthalmic Physiol Opt. 2002;22(1):10-25.

32. Schwartz RH, Schuman AJ, Wei LL. Instrument-based vision screening: update and review. (2014).

33. Silbert DI, Matta NS, Ely AL. Comparison of SureSight autorefractor and plusoptiX A09 photoscreener for vision screening in rural Honduras. J AAPOS. 2014;18(1):42-4.

34. - Jost RM, Yanni SE, Beauchamp CL, Stager Sr. DR, Stager Jr. D, Dao L, Birch EE. Beyond screening for risk factors: objective detection of strabismus and amblyopia. JAMA Ophthalmol (2014). It measures the sensitivity and specificity for the pediatric vision scanner in detecting strabismus and amblyopia in comparison with the suresight refractor which are operator independent screen tools.

35. American Academy of Pediatrics Section on Ophthalmology. Instrument-based pediatric vision screening policy statement. Pediatrics. 2012;130(5):983-6.

36. Toufeeq A, Oram AJ. School-entry vision screening in the United Kingdom: practical aspects and outcomes. Ophthalmic Epidemiol. 2014;21(4):210-6. 